\title{
3 Research Square

\section{Enhancing Carbon Utilization and Adsorption Performance of Sludge Derived Activated Carbon through Molten Salt Synthesis Method}

\section{En Shi}

Shenyang Jianzhu University

\section{Xinyu Wang}

Shenyang Jianzhu University

Miao Zhang ( $\sim$ zhangmiao@sjzu.edu.cn )

Shenyang Jianzhu University https://orcid.org/0000-0002-1802-6124

\section{Xin Wang}

Shenyang Jianzhu University

\section{Jianchun Gao}

Shenyang Jianzhu University

\section{Yunbin Zheng}

Shenyang Jianzhu University

\section{Research Article}

Keywords: Molten salt synthesis, Sludge derived activated carbon, Carbon mass balance, Carbon utilization potential, Adsorbing capacity

Posted Date: December 28th, 2021

DOI: https://doi.org/10.21203/rs.3.rs-1084525/v1

License: (c) (i) This work is licensed under a Creative Commons Attribution 4.0 International License. Read Full License 


\title{
Enhancing carbon utilization and adsorption performance of sludge derived activated carbon through molten salt synthesis method
}

\author{
En Shi ${ }^{\text {a }}$, Xinyu Wang ${ }^{\text {a }}$, Miao Zhang ${ }^{\text {b, }}$, Xin Wang ${ }^{\text {a }}$, Jianchun Gao ${ }^{\text {b }}$, Yunbin Zheng ${ }^{\text {a }}$ \\ a School of Municipal and Environmental Engineering, Shenyang Jianzhu University, Shenyang, 110168, \\ China \\ b School of Material Science and Engineering, Shenyang Jianzhu University, Shenyang, 110168, China \\ * Corresponding author details: Miao Zhang \\ E-mail: zhangmiao@sjzu.edu.cn
}

\begin{abstract}
Sewage sludge is carbonaceous organic material and an inevitable by-product of biological wastewater treatment process. The traditional sludge disposal routes may cause serious pollution risks, e. g. large amounts of carbon emissions. Molten salt synthesis (MSS) method could complete the carbonization and activation two processes within a single-step, and the complexity of chemical activation process could be significantly reduced. In this work, sludge derived activated carbon (SDAC) was prepared by MSS method with $\mathrm{ZnCl}_{2}$. The mass ratio of $\mathrm{ZnCl}_{2}$ to sludge had a significant effect on both the physicochemical properties and surface chemistry of SDAC. As the mass ratio of $\mathrm{ZnCl}_{2}$ to sludge was 1 , the maximum specific surface area of SDAC was $549.72 \mathrm{~m}^{2} / \mathrm{g}$. The maximum adsorbing capacity of methylene blue (MB) and $\mathrm{CO}_{2}$ were 0.0786 and $0.0575 \mathrm{mg} / \mathrm{mg}_{(\mathrm{SDAC})}$, respectively. The highest yield and carbon utilization potential of SDAC were $517.87 \mathrm{mg}(\mathrm{SDAC}) / \mathrm{g}_{(\text {(ludge })}$ and 178.56 $\mathrm{mg}_{\text {(carbon) }} / \mathrm{g}_{\text {(sludge) }}$, respectively. According to carbon mass balance, the total carbon mass in SDAC adsorbed $\mathrm{MB}$ and $\mathrm{CO}_{2}$ can be achieved to 203.00 and $186.68 \mathrm{mg}_{\text {(carbon) }} / \mathrm{g}_{\text {(sludge), }}$, respectively. It was suggested that MSS method can be used to reduce carbon emissions and improve carbon adsorption during SDAC preparation.
\end{abstract}

Keywords: Molten salt synthesis; Sludge derived activated carbon; Carbon mass balance; Carbon utilization potential; Adsorbing capacity

\section{Introduction}

Sewage sludge, the inevitable by-product generated in wastewater treatment process, contains harmful pollutants of pathogen, microorganism and heavy metals, which would result serious pollution problems(Chen et al., 2020). A few traditional sludge disposal 
routes include landfill, forestry, sea dumping and incineration, being phased out due to a more restrictive carbon policy and environmental drawbacks(Liu et al., 2021). Sewage sludge is rich in carbonaceous organic material with a large amount of exchangeable cations and surface adsorption sites(Gopinath et al., 2021; Tang et al., 2021). In order to utilize carbon in sludge reasonably, researchers convert sludge into activated carbon(Streit et al., 2021; Wu et al., 2020). Application of such low-cost sludge derived activated carbon (SDAC) for waste treatment purposes has a twofold ecological prominence, the conversion of a waste to a value-added material which alleviates the disposal problems and also the removal of pollutants(Heidarinejad et al., 2020; Wang and Wang, 2019; Zhao et al., 2020).

The molten salt synthesis (MSS) method is based on the use of a salt or multi-salts with low melting point as the molten medium for the desired synthesis(Liu et al., 2013). In the MSS process, the molten salt provides a favorable flux environment (from $100^{\circ} \mathrm{C}$ to over $1000^{\circ} \mathrm{C}$ ) with the solubility and diffusivity required for solid-phase reactions, which can greatly reduce the synthesis temperature. This MSS process has indeed already succeeded in the synthesis of various nano-powders, such as ferrites, titanates, niobates, mullite, aluminum borate, and wollastonite(Fechler and Antonietti, 2015). Compared with the conventional processes, MSS could complete the carbonization and activation two processes within a single-step, thus, the complexity of process and the reaction time of preparation activated carbon could be significantly reduced(Xue et al., 2018). To the best of our knowledge, little attention has been paid on the synthesis of activated carbon from sewage sludge by the MSS method.

In this study, SDAC was produced by adopting the simple and effective molten salt route. Sewage sludge was chosen as the carbon precursor, while the $\mathrm{ZnCl}_{2}$ served as the pore generator. The physicochemical features of the porous carbon were intensely characterized via elemental analysis, surface functional group, specific surface area and pore structure analysis. This porous carbon material was employed as an adsorbent for the removal of a well-known organic dye, methylene blue (MB), from aqueous media and $\mathrm{CO}_{2}$ in gaseous phase. The yield and adsorption performance of SDAC were calculated by carbon mass balance. The aims of the work are i) to prepare SDAC through MSS method, ii) to enhance the yield and adsorption performance of SDAC and iii) to analyze carbon mass balance of SDAC produced by MSS method.

\section{Experimental}

\subsection{Materials}

The experimental sewage sludge was collected from the secondary settling tank of 
Fushun Sanbaotun sewage treatment plant in Liaoning province, China. $\mathrm{ZnCl}_{2}$ and $\mathrm{MB}$ were purchased from Shanghai Aladdin Biochemical Technology Co., Ltd, China. Hydrochloric acid ( $\mathrm{HCl}$ ) was purchased from Tianjin Kemiou Chemical Reagent Co., Ltd, China.

\subsection{Preparation of SDAC}

After filtration, the sludge was vacuum dried in an oven at $105^{\circ} \mathrm{C}$ for $12 \mathrm{~h}$, then crushed and sieved through 100 mesh size. 1.5 grams of dried sludge and $\mathrm{ZnCl}_{2}$ were ground and mixed in a mortar with different mass ratio, the mixture was placed in a corundum boat and put into a tube furnace to carbonize under argon atmosphere at $500^{\circ} \mathrm{C}$ for $2 \mathrm{~h}$ with a heating rate of $5^{\circ} \mathrm{C} / \mathrm{min}$. After the reaction, the product was cooled down to room temperature and washed thoroughly with $5 \% \mathrm{HCl}$ solution and distilled water for three to four times to remove $\mathrm{ZnCl}_{2}$. The products were denoted as SDAC-n, where $\mathrm{n}$ represented the mass ratio of $\mathrm{ZnCl}_{2}$ to sludge.

\subsection{Characterization of SDAC}

Fourier transform infrared (FTIR) spectra of the products were detected on a Nicolet iS5 infrared spectrometer. Scanning electron microscopy (SEM) images were detected by ZEISS crossbeam 350 Scanning Electron Microscope. A Micromeritics ASAP 2020 analyzer was used to obtain textural properties of samples. The $\mathrm{N}_{2}$ adsorption/desorption curve and pore characteristics were detected under lowtemperature $(77 \mathrm{~K})$, and surface area and pore volume were calculated by BrunauerEmmett-Teller and the t-plot method calculates the pore volume of the micropores. $\mathrm{C}$, $\mathrm{H}, \mathrm{N}$ and $\mathrm{S}$ content in SDAC were determined by an Elementar UNI tube element analyzer.

\subsection{Adsorption experiment}

\subsection{1 $\mathrm{CO}_{2}$ adsorption measurement}

The $\mathrm{CO}_{2}$ adsorbing capacity of SDAC was determined by Micromeritics ASAP 2020 analyzer. Before the adsorption of $\mathrm{CO}_{2}$, the samples were degassed for at $200^{\circ} \mathrm{C}$ for 6 $\mathrm{h}$ to remove impurities adsorbed in the pores. The measurements were carried out at $298 \mathrm{~K}$ under a water bath.

\subsubsection{MB adsorption measurement}

$200 \mathrm{ml}$ of MB with the concentration of $40 \mathrm{mg} / \mathrm{L}$ were stirred at ambient conditions. $100 \mathrm{mg}$ of adsorbent was added to detect their adsorbing capacity. The absorbance of the solution was determined by Shanghai Metash UV5500 Spectrophotometer, and the concentration of residual MB in solution under different adsorption time was calculated according to the standard curve of MB solution. 


\subsection{Carbon mass balance}

The content of carbon in SDAC were analyzed by elemental analyzer. The yield ( $Y$, $\left.\mathrm{mg}_{(\mathrm{SDAC})} / \mathrm{g}_{(\text {(lludge })}\right)$ and carbon utilization potential $\left(U, \mathrm{mg}_{\text {(carbon) }} / \mathrm{g}_{\text {(sludge })}\right)$ of SDAC were calculated by equation (1) and (2), respectively, as follow

$$
\begin{gathered}
Y=\frac{m_{S D A C}}{m_{\text {sludge }}} \\
U=\frac{T C_{S D A C}}{m_{\text {sludge }}}=\frac{m_{S D A C} C_{S D A C}}{m_{\text {sludge }}}=Y \times c_{S D A C}
\end{gathered}
$$

where $m_{\text {sludge }}$ and $m_{\text {SDAC }}$ were dry weight of sludge and SDAC $(\mathrm{g})$, respectively, $T C_{\text {SDAC }}$ was carbon mass $(\mathrm{g}), c_{\mathrm{SDAC}}$ was carbon mass fraction of SDAC $\left(\mathrm{mg}_{\text {(carbon) }} / \mathrm{mg}_{(\mathrm{SDAC})}\right)$. The concentration of MB was used to calculate adsorbing capacity $\left(q_{\mathrm{t}}\right)$ as follow,

$$
q_{t}=\frac{V\left(C_{0}-C_{t}\right)}{m}
$$

where $\mathrm{V}$ was volume of solution (L), $\mathrm{c}_{0}$ was the initial concentration of MB in solution $(\mathrm{mg} / \mathrm{L}), \mathrm{c}_{\mathrm{t}}$ was concentration of $\mathrm{MB}(\mathrm{mg} / \mathrm{L})$. As adsorption equilibrium was achieved, the concentration of $\mathrm{MB}$ was $\mathrm{c}_{\mathrm{e}}(\mathrm{mg} / \mathrm{L})$, while the maximum adsorbing capacity was $q_{\mathrm{e}}$ $\left(\mathrm{mg} / \mathrm{mg}_{(\mathrm{SDAC})}\right)$.

The carbon mass balance of SDAC was calculated as below

$$
\text { Carbon mass }\left(\mathrm{mg}_{\text {(carbon })} / \mathrm{g}_{(\text {sludge })}\right)=Y \times\left(c_{\mathrm{SDAC}}+\mathrm{S}_{\mathrm{i}}\right)
$$

where $\mathrm{S}_{\mathrm{i}}$ included carbon adsorption potential for $\mathrm{CO}_{2}\left(\mathrm{~S}_{\mathrm{CO} 2}, \mathrm{mg}_{(\text {carbon })} / \mathrm{mg}_{(\mathrm{SDAC})}\right)$ and $\operatorname{MB}\left(S_{\mathrm{MB}}, \mathrm{mg}_{(\text {carbon })} / \mathrm{mg}_{(\mathrm{SDAC})}\right)$, respectively.

$$
\begin{aligned}
& S_{\mathrm{CO}_{2}}=q_{e, \mathrm{CO}_{2}} \times \omega_{\mathrm{CO}_{2}} \\
& S_{\mathrm{MB}}=q_{e, \mathrm{MB}} \times \omega_{\mathrm{MB}}
\end{aligned}
$$

where $q_{\mathrm{e}, \mathrm{CO} 2}$ and $q_{\mathrm{e}, \mathrm{MB}}$ were the maximum adsorbing capacity of $\mathrm{CO}_{2}\left(\mathrm{mg} / \mathrm{mg}_{(\mathrm{SDAC})}\right)$ and $\mathrm{MB}\left(\mathrm{mg} / \mathrm{mg}_{(\mathrm{SDAC})}\right)$, respectively. $\omega_{\mathrm{CO} 2}$ and $\omega_{\mathrm{MB}}$ were the carbon mass fraction of $\mathrm{CO}_{2}$ (carbon atom mass $/ \mathrm{CO}_{2}$ molecular mass) and $\mathrm{MB}$ (carbon atom mass/MB molecular mass), respectively.

\section{Results and discussion}

\subsection{Characterization of SDAC}

FTIR spectra was used to analyze surface functional groups of SDAC. Compared with dried sludge, a decrease in the number of absorption peaks of SDAC was observed. It was indicated that calcination caused decomposition and volatilization of surface functional group in sludge (Fig. S1). The bands at 3417 and $3130 \mathrm{~cm}^{-1}$ were attributed to the stretching vibration of $\mathrm{O}-\mathrm{H}$ and N-H, and the bands at 2345 and $2369 \mathrm{~cm}^{-1}$ were owing to the adsorption of $\mathrm{CO}_{2}$. The stretching vibration of $\mathrm{C}=\mathrm{O}$ and $\mathrm{C}=\mathrm{C}$ resulted in the peak at around $1600 \mathrm{~cm}^{-1}$, indicating that aromatic rings and carbonyls existed in the surface of SDAC. The band from 400 to $850 \mathrm{~cm}^{-1}$ due to the presence of an out of 
plane bending of $\mathrm{C}-\mathrm{H}$. The broad band at around $1030 \mathrm{~cm}^{-1}$ can be ascribed to C-O bonds of phenols, carboxylic groups or alcohols. The band positions and areas changed with the change of the mass ratio of $\mathrm{ZnCl}_{2}$ to sludge, indicating that the types and quantities of carbonaceous species were different on SDAC-n (Fig. 1a).

The morphology of the products was characterized by SEM. As shown in Fig. S2, the mass ratio of $\mathrm{ZnCl}_{2}$ to sludge had a dramatic effect on the porous structure characteristics. The sludge calcined without $\mathrm{ZnCl}_{2}$ had dense structure and almost no pores. With the increase of the mass of $\mathrm{ZnCl}_{2}$, the porosity of the sample surface increased. A well-dispersed pore structure can be observed on the surface of SDAC-1, which may have a beneficial effect on its adsorption capacity. However, when the mass ratio of $\mathrm{ZnCl}_{2}$ to sludge in the system was further increased, excessive $\mathrm{ZnCl}_{2}$ will lead to the formation of a denser surface in the products.
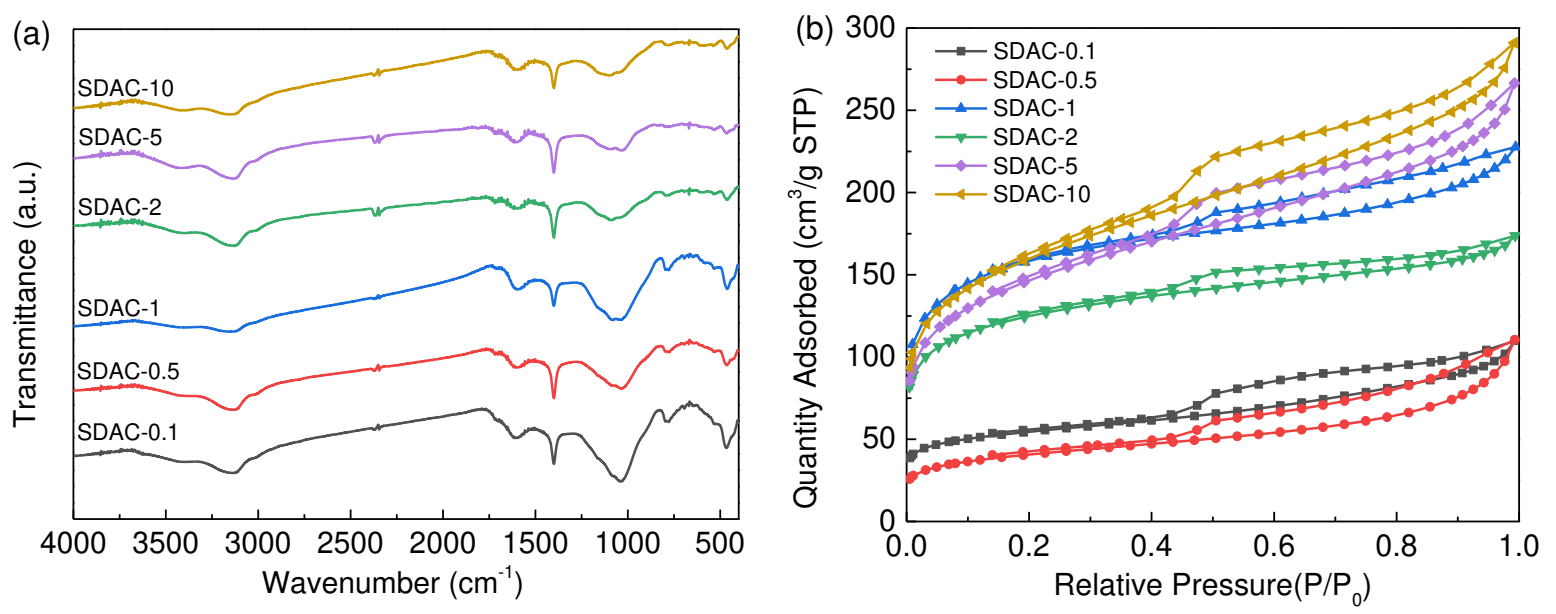

Fig. 1 (a) FTIR spectra and (b) $\mathrm{N}_{2}$ adsorption/desorption isotherms of SDAC-n

$\mathrm{N}_{2}$ sorption experiment was carried out to further analyze the pore properties of the products. The $\mathrm{N}_{2}$ adsorption/desorption isotherm of SDAC-n showed type-IV isotherm according to the IUPAC classification, the existence of hysteresis loops indicated that there were mesopores and micropores in the system (Fig. 1b). The corresponding quantitative data were summarized in Table $\mathrm{S} 1$. As the mass ratio of $\mathrm{ZnCl}_{2}$ to sludge increased from 0.1 to 10 , the pore volume increased from 0.17 to $0.45 \mathrm{~cm}^{3} / \mathrm{g}$. The results showed that the existence of $\mathrm{ZnCl}_{2}$ was benefit for the formation of pore structure, indicating that $\mathrm{ZnCl}_{2}$ was a template in the formation of the products(Shi et al., 2021; Zhang et al., 2020). With the increase of $\mathrm{ZnCl}_{2}$, the micropore area and volume of the product first increased and then decreased, indicating that the addition of a small amount of $\mathrm{ZnCl}_{2}$ was conducive to the formation of micropores. When $\mathrm{ZnCl}_{2}$ was excessive, the microporous structure was destroyed and mesopores and macropores were formed. The specific surface area of SDAC-1 was $549.72 \mathrm{~m}^{2} / \mathrm{g}$. Further increasing 
of $\mathrm{ZnCl}_{2}$, the specific surface area first decreased and then increased, accompanied by the decrease of micropore area and volume. The above results showed that with the increase of $\mathrm{ZnCl}_{2}$, mesopores and macropores dominate and lead to the increase of specific surface area. Thus, the mass ratio of $\mathrm{ZnCl}_{2}$ to sludge in MSS method had a significant effect on the proportion of micropore, mesopore and macropore in SDAC.

\subsection{Adsorption properties of SDAC}

\subsection{1 $\mathrm{CO}_{2}$ adsorption}

The adsorbing capacity of $\mathrm{CO}_{2}$ will be affected by the textural properties of SDAC. The content of $\mathrm{ZnCl}_{2}$ had a great influence on the $\mathrm{CO}_{2}$ adsorbing capacity of SDAC (Fig. 2a). From the experimental results, the $\mathrm{CO}_{2}$ adsorbing capacity of SDAC-0.1 was low, SDAC-0.5 and SDAC-1 showed better $\mathrm{CO}_{2}$ adsorbing capacity, which was related to the pore properties of the samples. Combined with pore property analysis, we found that the micropore volume of porous materials played a decisive role in $\mathrm{CO}_{2}$ adsorption at low pressure and ambient temperature. The adsorbing capacity of $\mathrm{CO}_{2}$ was also related to the specific surface area of the adsorbent. Although the micropore volume of SDAC-5 and SDAC-10 was similar, SDAC-10 showed better $\mathrm{CO}_{2}$ adsorption owing to its large specific surface area. At about 1.0 bar, the $\mathrm{CO}_{2}$ adsorbing capacity of SDAC1 was $0.0575 \mathrm{mg} / \mathrm{mg}_{(\mathrm{SDAC})}$, which was equivalent to those of porous carbon synthesized by other methods(de Andrés et al., 2013; Y1ld1z et al., 2019).
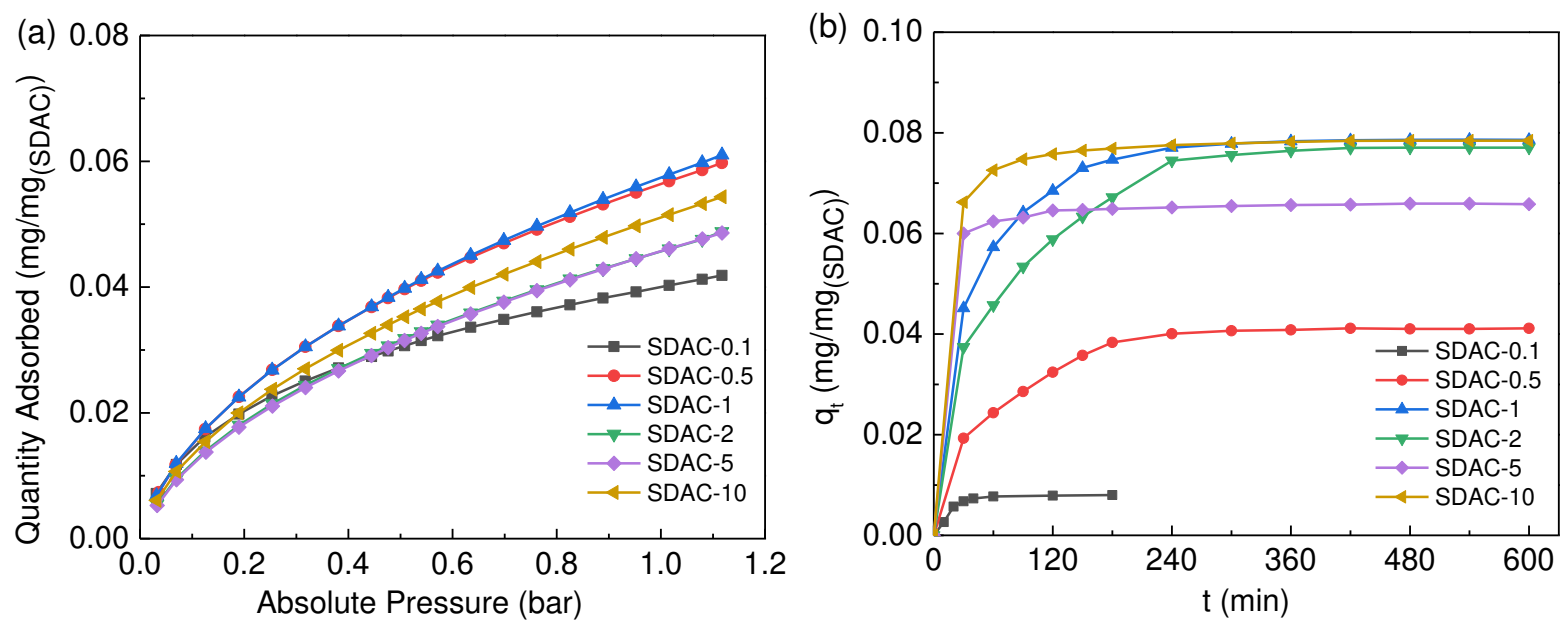

Fig. 2 Adsorption capacity of (a) $\mathrm{CO}_{2}$ and (b) MB on SDAC-n

\subsubsection{MB adsorption}

SDAC had a unique pore structure, which not only had a great adsorbing capacity of $\mathrm{CO}_{2}$, but also can be used to adsorb $\mathrm{MB}$ in liquid phase. Owing to the smaller particle size and larger pore volume, the adsorption equilibrium of SDAC-5 and SDAC-10 can be easily reached within 30 minutes (Fig. 2b). After 120 minutes, the MB adsorbing 
capacity of SDAC-1 gradually increases and exceeds that of SDAC-5, which may be due to the larger specific surface area of SDAC-1. After 240 minutes, the adsorption of all samples reached equilibrium, the maximum MB adsorbing capacity of SDAC-1 and SDAC-10 were similar, both of which were about $0.0786 \mathrm{mg} / \mathrm{mg}_{(\mathrm{SDAC})}$. The adsorbing capacity of $\mathrm{CO}_{2}$ and $\mathrm{MB}$ on SDAC-n were listed in Table S2. According to the results, SDAC-1 had the maximum adsorbing capacity. It was suggested that the optimum mass ratio of $\mathrm{ZnCl}_{2}$ to sludge was 1 for both $\mathrm{CO}_{2}$ and $\mathrm{MB}$.

\subsection{Carbon utilization potential}

$\mathrm{ZnCl}_{2}$ had a positive effect on carbon mass fraction and utilization potential of SDAC. In the process of preparing SDAC by molten salt method, appropriate amount of $\mathrm{ZnCl}_{2}$ was beneficial to improve the carbon content in the products (Table S3). The yield of SDAC-0.1 was $494.73 \mathrm{mg}_{(\mathrm{SDAC})} / \mathrm{g}_{(\text {(sludge })}$, while carbon mass fraction and utilization

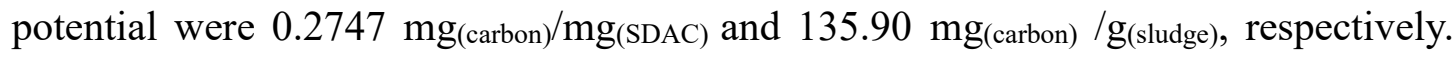
This meant the addition of $\mathrm{ZnCl}_{2}$ resulted in the decline of yield, but increase of carbon mass fraction and utilization potential. For SDAC-0.5 and SDAC-1, the carbon utilization potential increased to 159.85 and $178.56 \mathrm{mg}$ (carbon) $/ \mathrm{g}_{\text {(sludge), }}$, respectively (Fig. 3). However, further increasing the content of $\mathrm{ZnCl}_{2}$, the carbon utilization potential decreased. It was indicated that excessive $\mathrm{ZnCl}_{2}$ in the system will reduce the yield of SDAC. According to the analysis results of utilization potential, the addition of $\mathrm{ZnCl}_{2}$ resulted in the increase of carbon mass fraction, and the optimum mass ratio of $\mathrm{ZnCl}_{2}$ to sludge was 1 . In MSS method, $\mathrm{ZnCl}_{2}$ was used as both template and solvent for the formation of porous carbon. Comparing with impregnating method, most carbon in sludge can be converted into activated carbon by MSS method without oxygen molecules and atoms dissolved in water.
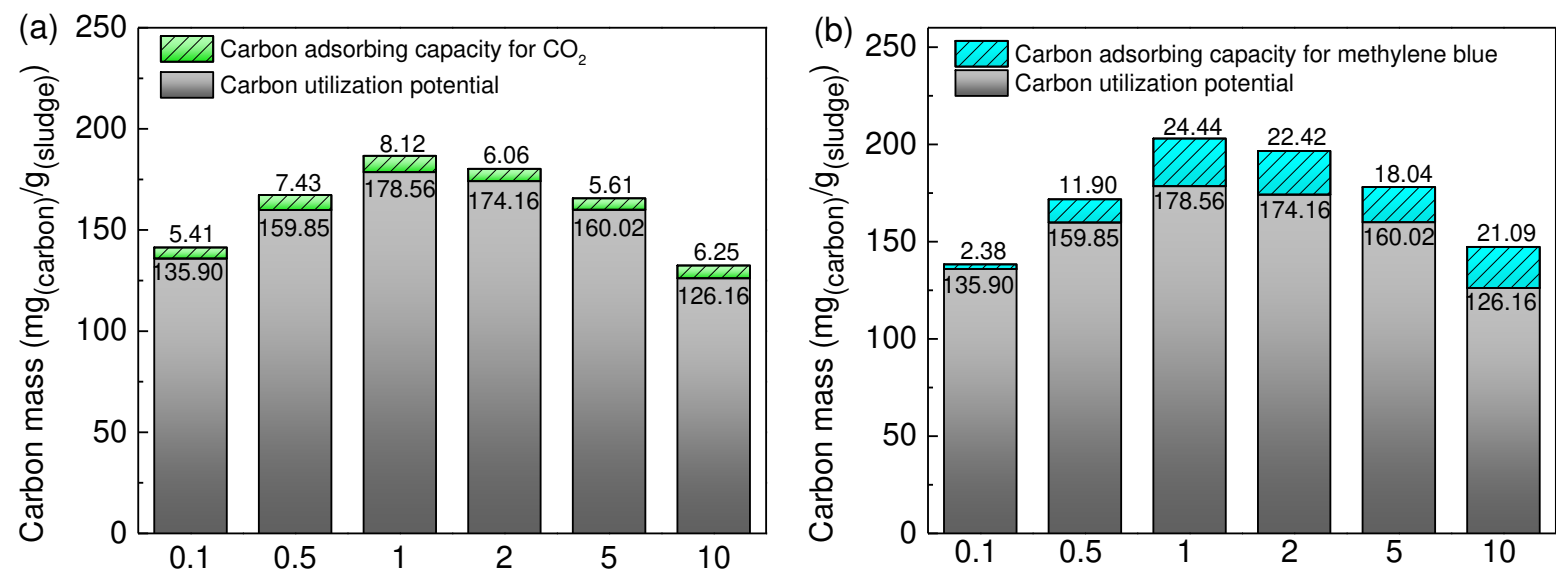

Fig. 3 Carbon mass balance of SDAC by MSS method with different mass ratio of $\mathrm{ZnCl}_{2}$ to sludge 


\subsection{Carbon mass balance in MSS method}

The carbon mass balance of sludge treated by MSS method included the carbon utilization potential of SDAC and the carbon adsorbing capacity of $\mathrm{MB}$ and $\mathrm{CO}_{2}$. The carbon mass was calculated based on equations (2)-(6). According to the data processing results, SDAC-1 showed relatively excellent performance. The total carbon mass in SDAC adsorbed $\mathrm{MB}$ and $\mathrm{CO}_{2}$ can be achieved to 203.00 and 186.68 $\mathrm{mg}_{\text {(carbon) }} / \mathrm{g}_{\text {(sludge), }}$, respectively (Fig. 3). The total carbon mass in SDAC decreased along with the increase of $\mathrm{ZnCl}_{2}$ mass. For SDAC-10, carbon mass in SDAC adsorbed MB and $\mathrm{CO}_{2}$ decreased to 147.25 and $132.41 \mathrm{mg}_{\text {(carbon) }} / \mathrm{g}_{\text {(sludge), respectively. It was }}$ suggested that large quantities of carbon were transformed into SDAC through MSS method, resulting in reduction of carbon emissions. However, the excess $\mathrm{ZnCl}_{2}$ can cause a decline of both carbon utilization potential and adsorbing capacity. In MSS method, carbon utilization potential was higher than adsorbing capacity of both $\mathrm{CO}_{2}$ and MB. Thus, carbon utilization potential was an important index for sludge treatment.

\section{Conclusion}

In this work, SDAC was prepared by MSS method with $\mathrm{ZnCl}_{2}$. The mass ratio of $\mathrm{ZnCl}_{2}$ to sludge had a significant effect on both the physicochemical properties and surface chemistry of SDAC. The maximum adsorbing capacity of $\mathrm{MB}$ and $\mathrm{CO}_{2}$ was obtained as the mass ratio of $\mathrm{ZnCl}_{2}$ to sludge was 1 . It exhibited the maximum adsorbing capacity of $\mathrm{MB}$ and $\mathrm{CO}_{2}$ were 0.0786 and $0.0575 \mathrm{mg} / \mathrm{mg}_{(\mathrm{SDAC})}$, respectively. The highest yield and carbon utilization potential of SDAC were 517.87 $\mathrm{mg}_{\text {(SDAC) }} / \mathrm{g}_{\text {(sludge) }}$ and $178.56 \mathrm{mg}$ (carbon) $/ \mathrm{g}_{\text {(sludge) }}$, respectively. According to carbon mass balance, the total carbon mass in SDAC adsorbed $\mathrm{MB}$ and $\mathrm{CO}_{2}$ can be achieved to 203.00 and $186.68 \mathrm{mg}_{\text {(carbon) }} / \mathrm{g}_{\text {(sludge) }}$, respectively. It was suggested that MSS method can be used to reduce carbon emissions and improve carbon adsorption during SDAC preparation.

\section{Acknowledgements}

This work was supported by the Fundamental Research Funds for Colleges and Universities in Liaoning Province, China (grant number lnjc202012 and lnqn202020).

\section{Contributions}

ES and MZ designed the research. ES and XW collected the data. XW, JG, YZ analyzed the data. ES and MZ wrote the article.

\section{Conflict of interest}

Authors declare no competing financial interest. 


\section{Reference}

Chen, Y.-d., Wang, R., Duan, X., Wang, S., Ren, N.-q., Ho, S.-H. (2020) Production, properties, and catalytic applications of sludge derived biochar for environmental remediation. Water Res. 187: 116390.

de Andrés, J.M., Orjales, L., Narros, A., de la Fuente, M.d.M., Rodríguez, M.E. (2013) Carbon dioxide adsorption in chemically activated carbon from sewage sludge. J. Air Waste Manage. Assoc. 63(5): $557-564$.

Fechler, N., Antonietti, M. (2015) Domino games: Controlling structure and patterns of carbon nanomaterials in 2D \& 3D. Nano Today 10(5): 593-614.

Gopinath, A., Divyapriya, G., Srivastava, V., Laiju, A.R., Nidheesh, P.V., Kumar, M.S. (2021)

Conversion of sewage sludge into biochar: A potential resource in water and wastewater treatment. Environ. Res. 194: 110656.

Heidarinejad, Z., Dehghani, M.H., Heidari, M., Javedan, G., Ali, I., Sillanpää, M. (2020) Methods for preparation and activation of activated carbon: a review. Environ. Chem. Lett. 18(2): 393-415.

Liu, H., Basar, I.A., Nzihou, A., Eskicioglu, C. (2021) Hydrochar derived from municipal sludge through hydrothermal processing: A critical review on its formation, characterization, and valorization. Water Res. 199: 117186.

Liu, X., Fechler, N., Antonietti, M. (2013) Salt melt synthesis of ceramics, semiconductors and carbon nanostructures. Chem. Soc. Rev. 42(21): 8237-8265.

Shi, E., Wang, X., Zhang, M., Fang, Y., Gao, J., Wang, X., Zheng, Y. (2021) Direct synthesis of hierarchical porous polymer nanoparticles from nitrile monomers and its application for methylene blue adsorption. Mater. Res. Express 8(3): 035001.

Streit, A.F.M., Collazzo, G.C., Druzian, S.P., Verdi, R.S., Foletto, E.L., Oliveira, L.F.S., Dotto, G.L. (2021) Adsorption of ibuprofen, ketoprofen, and paracetamol onto activated carbon prepared from effluent treatment plant sludge of the beverage industry. Chemosphere 262: 128322.

Tang, Z., Zhao, S., Qian, Y., Jia, H., Gao, P., Kang, Y., Lichtfouse, E. (2021) Formation of persistent free radicals in sludge biochar by hydrothermal carbonization. Environ. Chem. Lett. 19(3): 2705-2712. Wang, J., Wang, S. (2019) Preparation, modification and environmental application of biochar: A review. J. Clean. Prod. 227: 1002-1022.

Wu, H.-Y., Chen, S.S., Liao, W., Wang, W., Jang, M.-F., Chen, W.-H., Ahamad, T., Alshehri, S.M., Hou, C.-H., Lin, K.-S., Charinpanitkul, T., Wu, K.C.W. (2020) Assessment of agricultural waste-derived activated carbon in multiple applications. Environ. Res. 191: 110176.

Xue, P., Wu, H., Lu, Y., Zhu, X. (2018) Recent progress in molten salt synthesis of low-dimensional perovskite oxide nanostructures, structural characterization, properties, and functional applications: A review. J. Mater. Sci. Technol. 34(6): 914-930. 
Yıldız, Z., Kaya, N., Topcu, Y., Uzun, H. (2019) Pyrolysis and optimization of chicken manure wastes in fluidized bed reactor: $\mathrm{CO}_{2}$ capture in activated bio-chars. Process Saf. Environ. Prot. 130: 297-305. Zhang, M., Liu, L., He, T., Ju, X., Chen, P. (2020) Molten salt assisted pyrolysis approach for the synthesis of nitrogen-rich microporous carbon nanosheets and its application as gas capture sorbent. Microporous Mesoporous Mater. 300: 110177.

Zhao, Y.-x., Li, X.-y., Tian, C., Wang, J.-x. (2020) Production of carbon-doped titanium dioxide (C$\mathrm{TiO}_{2}$ ) from polytitanium-coagulated sludge as an adsorbent or photocatalyst for pollutant removals. J. Clean. Prod. 267: 121979. 


\section{Supplementary Files}

This is a list of supplementary files associated with this preprint. Click to download.

- SupportingInformation.docx 